\title{
INSECTICIDAL, ANTIBACTERIAL, AND ANTIRADICAL ACTIVITY OF NICOTIANA PLUMBAGINIFOLIA VIV. (SOLANACEAE)
}

\author{
PRASHITH KEKUDA TR ${ }^{1}$, RAGHAVENDRA HL ${ }^{2 *}$, RAJESH MR ${ }^{1}$, AVINASH HC ${ }^{1}$
}

${ }^{1}$ Department of Microbiology, S.R.N.M.N College of Applied Sciences, N.E.S Campus, Shivamogga, Karnataka, India. ${ }^{2}$ Department of Biochemistry, School of Medicine, Wollega University, Nekemte, Ethiopia. Email: raghu.biogem@gmail.com

Received: 11 June 2017, Revised and Accepted: 21 July 2017

\section{ABSTRACT}

Objectives: Nicotiana plumbaginifolia Viv. belongs to the family Solanaceae. The present study was carried out to determine insecticidal, antibacterial, and antiradical activity of aerial parts of $N$. plumbaginifolia.

Methods: Extraction was carried out by maceration process using methanol. Insecticidal activity was assessed, in terms of larvicidal effect, against II and IV instar larvae of Aedes aegypti. Antibacterial activity was evaluated against a panel of 7 bacteria by agar well diffusion assay. Antiradical activity was determined using 1,1-diphenyl-2-picrylhydrazyl (DPPH) and 2,2-azinobis 3-ethylbenzothiazoline 6-sulfonate (ABTS) free radical scavenging assays.

Results: The extract was found to cause dose-dependent mortality of larvae of $A$. aegypti. The lethal concentration 50 value of extract for II and IV instar larvae was found to be 0.41 and $0.99 \mathrm{mg} / \mathrm{ml}$, respectively. Extract was effective in inhibiting all bacteria. Gram-positive bacteria displayed marked susceptibility when compared to Gram-negative bacteria. Bacillus cereus and Escherichia coli were susceptible to highest and least extent, respectively. Extract scavenged both DPPH radicals and ABTS radicals dose dependently. Extract scavenged ABTS radicals more efficiently (inhibitory concentration [ $\mathrm{IC}_{50}$ ] value $13.51 \mu \mathrm{g} / \mathrm{ml}$ ) when compared to DPPH radicals ( $\mathrm{IC}_{50}$ value $17.43 \mu \mathrm{g} / \mathrm{ml}$ ).

Conclusions: The plant $N$. plumbaginifolia appears to be a promising resource for developing agents with insecticidal, antibacterial, and antiradical activity. The observed bioactivities could be attributed to the presence of phytochemicals which are to be isolated, characterized, and subjected for bioactivity determinations. The plant can be used to prevent arboviral diseases, infectious diseases, and oxidative damage.

Keywords: Nicotiana plumbaginifolia, Maceration, Larvicidal, Aedes aegypti, Agar well diffusion, Free radical, 1,1-Diphenyl-2-picrylhydrazyl, 2,2-Azinobis 3-ethylbenzothiazoline 6-sulfonate.

(C) 2017 The Authors. Published by Innovare Academic Sciences Pvt Ltd. This is an open access article under the CC BY license (http://creativecommons. org/licenses/by/4. 0/) DOI: http://dx.doi.org/10.22159/ajpcr.2017.v10i11.20559

\section{INTRODUCTION}

Mosquito-borne diseases are prevalent in many countries across the world and are known to affect millions of people every year. Diseases such as malaria, dengue, yellow fever, and Japanese encephalitis that are transmitted by mosquitoes are known to cause massive mortality and morbidity in human population. Hence, it is very important to prevent and control mosquito-borne diseases. Synthetic insecticides such as organochlorine and organophosphate compounds are extensively used for controlling mosquitoes. However, their extensive use is associated with certain negative health and environmental impacts such as residual content in environment, adverse effects on human health, and other non-target populations. Besides, they are costly, non-biodegradable, and may not be effective as insects readily develop resistance against them. This situation triggered immense interest in scientific community to look for alternative strategies for mosquito control and the use of botanicals as pesticides is shown to be one of the promising strategies [1-8].

Many microorganisms are known to cause diseases in humans and result in considerable morbidity and mortality. Discovery of antibiotics is considered as one of the most important milestones in the field of medicine. Therapy using antibiotics has saved plenty of people from death since discovery. However, the use of antibiotics suffers from several drawbacks among which the development of resistance in pathogenic bacteria (due to overuse and abuse of antibiotics) seems to be most important one. Besides, high cost and possible side effects of antibiotics limit their use. This triggered much interest in scientific community to search alternative strategies for disease therapy. Natural products offer a promising alternative for treatment of infectious diseases. Plants, plant-based formulations, and purified compounds from plants have shown inhibitory activity against a variety of pathogenic bacteria including drug-resistant strains [9-17].

Molecular oxygen is very essential to generate energy and is relatively harmless. However, during aerobic metabolism and exposure to conditions such as drugs, radiations, and pollution, some reactive species are produced from oxygen. These species are termed as reactive oxygen species and include free radicals such as superoxide radicals and hydroxyl radicals and non-radical species such as hydrogen peroxide. Free radicals are chemical species having an unpaired electron in an atomic orbital and are known to be unstable and highly reactive. They are highly reactive and are known to damage proteins, lipids, and nucleic acids. Free radicals are known to cause oxidative damage which is implicated in cancer, aging, cardiovascular diseases, and neurodegenerative disorders. Cells have an antioxidant defense system which includes enzymatic and non-enzymatic system. A balance should always exist between free radical generation and antioxidant defense to have normal health. Interest in natural antioxidants is triggered due to suspected negative effects of synthetic antioxidants. Botanicals are proven to be promising resources of agents with antioxidant potential [12,16,18-21].

Nicotiana plumbaginifolia Viv. (Solanaceae) is an erect, shallow-rooted, pubescent, annual, or perennial herb and is 1-3 m tall. It is commonly called Tex-Mex tobacco and wild tobacco. It grows in damp places near water. It is originated in West Indies and Mexico [22-25]. The plant 
is used traditionally as an insecticide and to treat various ailments such as toothache, nausea, wounds, pain, itching, syphilis, and piles [8,23,26-30]. N. plumbaginifolia is shown to exhibit bioactivities such as antioxidant [24], antimicrobial [24,31], insecticidal [8], analgesic [23], neuropharmacological [23], and hepatoprotective [32] activities. The present study was carried out to investigate insecticidal, antibacterial, and free radical scavenging activity of aerial parts of $N$. plumbaginifolia.

\section{METHODS}

\section{Collection and extraction of $N$. plumbaginifolia}

The plant was collected near Matturu, Shivamogga, Karnataka, during January 2017. The plant was identified by Prof. D. Rudrappa, Department of Botany, S.R.N.M.N College of Applied Sciences. The plant material (aerial parts) was washed to remove extraneous matter, dried under shade and powdered. Extraction of plant material was carried out by maceration process using methanol. In a stoppered container, the powdered material $(10 \mathrm{~g})$ was left in methanol $(100 \mathrm{ml})$ for $48 \mathrm{hrs}$ with occasional stirrings. The content was filtered and the filtrate was evaporated at room temperature, and crude extract was obtained $[17,33]$

\section{Insecticidal activity of $N$. plumbaginifolia}

We determined insecticidal activity of extract (in terms of larvicidal potential) against II and IV instar larvae of Aedes aegypti. In brief, 20 larvae (II and IV instar) were transferred into flasks containing $50 \mathrm{ml}$ of water with different concentrations of extract $0.0-2.0 \mathrm{mg} / \mathrm{ml}$. The flasks were incubated for $24 \mathrm{hrs}$. Later, the number of dead larvae in each of the flasks was counted, and the mortality rate was determined using the following formula:

Mortality of larvae $(\%)=($ Number of dead larvae/total number of larvae $) \times 100$. Lethal concentration $50\left(\mathrm{LC}_{50}\right)$ value was calculated using linear regression analysis. $\mathrm{LC}_{50}$ value indicates the concentration of extract which is required to cause $50 \%$ mortality $[4,5]$

\section{Antibacterial activity of $N$. plumbaginifolia}

Agar well diffusion method was carried out to investigate antibacterial potential of extract against four Gram-positive bacteria, namely, Staphylococcus aureus NCIM 5345, Staphylococcus epidermidis NCIM 2493, Bacillus subtilis NCIM 2063, and Bacillus cereus NCIM 2016 and three Gram-negative bacteria, namely, Escherichia coli NCIM 2065, Pseudomonas aeruginosa NCIM 2200, and Salmonella typhimurium NCIM 2501. 24 hrs old nutrient broth (HiMedia, Mumbai) cultures of test bacteria were swab inoculated on sterile nutrient agar (HiMedia, Mumbai) plates aseptically followed by punching wells of $8 \mathrm{~mm}$ diameter using sterile cork borer. $100 \mu \mathrm{l}$ of extract $(20 \mathrm{mg} / \mathrm{ml}$ of dimethyl sulfoxide [DMSO]), chloramphenicol (reference antibiotic; $1 \mathrm{mg} / \mathrm{ml}$ of sterile water), and DMSO were transferred into respective wells in the inoculated plates. The plates were incubated for $24 \mathrm{hrs}$ at $37^{\circ} \mathrm{C}$, and the zones of inhibition were measured using a ruler $[17,33]$.

\section{Free radical scavenging activity of $N$. plumbaginifolia}

1,1-diphenyl-2-picrylhydrazyl (DPPH) radical scavenging activity Various concentrations of extract and ascorbic acid $(6.25-200 \mu \mathrm{g} / \mathrm{ml})$ were prepared in $1 \mathrm{ml}$ of methanol in clean and dry tubes. To each of the tube, $3 \mathrm{ml}$ of DPPH radical solution was added and the tubes were incubated in the dark for 30 minutes. The absorbance was measured spectrophotometrically at $520 \mathrm{~nm}$. Methanol replacing extract served as control. Radical scavenging potential of extract was determined using the following formula:

DPPH radical scavenging potential $(\%)=($ Ac-At $/ A c) \times 100$, where Ac and At denote the absorbance of DPPH control and absorbance of DPPH in the presence of extract/ascorbic acid, respectively. The inhibitory concentration $\left(\mathrm{IC}_{50}\right)$ value was calculated using linear regression analysis, and the value obtained indicates the concentration of extract/ ascorbic acid required to scavenge $50 \%$ of free radicals $[17,33]$.

\section{2,2-azinobis 3-ethylbenzothiazoline 6-sulfonate (ABTS) radical scavenging activity}

ABTS radicals were generated by mixing ABTS stock $(7 \mathrm{mM})$ with potassium persulfate $(2.45 \mathrm{mM})$ and leaving the reaction mixture to stand for $16 \mathrm{hrs}$ in dark. $3 \mathrm{ml}$ of ABTS radical solution was transferred into each of the tubes containing various concentrations $(6.25-200 \mu \mathrm{g} / \mathrm{ml})$ of extract and ascorbic acid. The tubes were incubated for 30 minutes in the dark, and the absorbance of content of each tube was measured spectrophotometrically at $730 \mathrm{~nm}$. Methanol replacing extract served as control. ABTS radical scavenging potential of extract was determined using the formula:

Scavenging potential $(\%)=(\mathrm{Ac}-\mathrm{At} / \mathrm{Ac}) \times 100$, where Ac and At denote the absorbance of ABTS control and absorbance of ABTS in the presence of extract/ascorbic acid, respectively. The $\mathrm{IC}_{50}$ value was calculated using linear regression analysis, and the value obtained indicates the concentration of extract/ascorbic acid required to scavenge $50 \%$ of free radicals $[17,33]$

\section{RESULTS AND DISCUSSION}

\section{Insecticidal activity of $N$. plumbaginifolia}

Prevention of mosquito-borne diseases involves various strategies. One of the important methods of prevention is the killing of mosquito larvae in stagnant water. In the present study, we evaluated insecticidal potential of $N$. plumbaginifolia against larvae of $A$. aegypti and the result is shown in Fig. 1. The extract showed dose-dependent mortality of larvae. The extract caused $>50 \%$ of mortality of II and IV instar larvae at concentration $0.5 \mathrm{mg} / \mathrm{ml}$ and higher and $1 \mathrm{mg} / \mathrm{ml}$ and higher, respectively. Extract was found to be more effective against II instar larvae when compared to IV instar larvae. The $\mathrm{LC}_{50}$ value of extract for II and IV instar larvae was found to be $0.41 \mathrm{mg} / \mathrm{ml}$ and $0.99 \mathrm{mg} / \mathrm{ml}$, respectively. In an earlier study, Singh et al. [8] evaluated larvicidal potential of leaf extract of $N$. plumbaginifolia against Anopheles stephensi and found dose-dependent larvicidal activity. It is clear from the result of present study that extract is more lethal to initial stages of larval development. Similar result was observed in the study of Singh et al. [8] in which the leaf extract of $N$. plumbaginifolia exhibited marked larvicidal effect against initial stages of larval development.

\section{Antibacterial activity of $N$. plumbaginifolia}

Higher plants are considered to be promising resources of agents with activity against pathogenic microbes including drug-resistant bacteria $[17,34,35]$. In the present study, we evaluated antibacterial potential of $N$. plumbaginifolia by agar well diffusion assay which is one of the most widely used in vitro assays to determine antibacterial potential of plant extracts. In this assay, the presence of an inhibition zone around the well is taken as positive result while the absence of inhibition zone is negative for antibacterial activity [17,36-38]. The extract of $N$. plumbaginifolia was found to exhibit inhibitory activity against all test bacteria with zone of inhibition ranging from $1.0 \mathrm{~cm}$ to $1.8 \mathrm{~cm}$. The extract was more effective against Gram-positive bacteria when compared to Gram-negative bacteria. B. cereus and E. coli were inhibited by extract to highest and least extent, respectively. $S$. aureus and S. epidermidis were inhibited to similar extent (zone of inhibition $1.4 \mathrm{~cm}$ ). Inhibitory activity of extract against $P$. aeruginosa and S. typhimurium was similar (zone of inhibition $1.2 \mathrm{~cm}$ ). Reference antibiotic caused marked antibacterial activity when compared to extract while DMSO did not show inhibition of test bacteria (Table 1). In an earlier study, Singh et al. [22] showed antibacterial potential of aqueous extract obtained from leaves of $N$. plumbaginifolia against Gram-positive and Gram-negative bacteria. Recently, Ajaib et al. [24] observed potent antibacterial activity in leaf, stem, root, and fruit of N. plumbaginifolia.

\section{DPPH radical scavenging activity of $N$. plumbaginifolia}

The assay involving scavenging of DPPH radicals was developed by Blois. It is one of the most widely used in vitro assays for determining free radical scavenging nature of various kinds of samples including 
Table 1: Antibacterial activity of Nicotiana plumbaginifolia

\begin{tabular}{llll}
\hline \multirow{2}{*}{ Test bacteria } & \multicolumn{3}{l}{ Zone of inhibition in cm } \\
\cline { 2 - 4 } & Extract & Antibiotic & DMSO \\
\hline Bacillus cereus & $1.80 \pm 0.10$ & $3.80 \pm 0.00$ & $0.00 \pm 0.00$ \\
Bacillus subtilis & $1.60 \pm 0.00$ & $3.66 \pm 0.05$ & $0.00 \pm 0.00$ \\
Staphylococcus aureus & $1.40 \pm 0.10$ & $3.40 \pm 0.10$ & $0.00 \pm 0.00$ \\
Staphylococcus epidermidis & $1.40 \pm 0.00$ & $3.10 \pm 0.00$ & $0.00 \pm 0.00$ \\
Pseudomonas aeruginosa & $1.20 \pm 0.00$ & $2.96 \pm 0.05$ & $0.00 \pm 0.00$ \\
Escherichia coli & $1.00 \pm 0.00$ & $2.50 \pm 0.00$ & $0.00 \pm 0.00$ \\
Salmonella typhimurium & $1.23 \pm 0.05$ & $2.80 \pm 0.00$ & $0.00 \pm 0.00$ \\
\hline
\end{tabular}

DMSO: Dimethyl sulfoxide

plant extracts. The assay is simple and cheaper and uses stable, organic, nitrogen-centered free radical which need not be generated as in case of ABTS assay. Substances having the potential of donating hydrogen will convert the purple-colored DPPH radical into a yellow-colored non-radical form DPPHH which can be monitored at $515-520 \mathrm{~nm}$ spectrophotometrically [16,17,21,33,39-42]. In the present study, we evaluated radical scavenging potential of extract of N. plumbaginifolia by DPPH assay, and the result is shown in Fig. 2. The extract exhibited concentration-dependent scavenging of DPPH radicals with an $\mathrm{IC}_{50}$ value of $17.43 \mu \mathrm{g} / \mathrm{ml}$. A scavenging activity of $>50 \%$ was observed at extract concentration of $25 \mu \mathrm{g} / \mathrm{ml}$ and higher. When compared to extract, ascorbic acid scavenged DPPH radicals more efficiently with an $\mathrm{IC}_{50}$ value of $3.06 \mu \mathrm{g} / \mathrm{ml}$. The study of Ajaib et al. [24] showed concentration-dependent scavenging of DPPH radicals by different parts of $N$. plumbaginifolia. In the present study, the radical scavenging potential by $N$. plumbaginifolia was lesser than that of ascorbic acid; however, it is clear that the extract possesses hydrogen-donating property, and hence, it can act as a free radical scavenger.

\section{ABTS radical scavenging activity of $N$. plumbaginifolia}

The assay involving scavenging of ABTS radicals is another popular in vitro antiradical assays. Unlike DPPH assay, it requires the generation of ABTS radicals which can be done by reacting ABTS stock with an oxidizing agent such as potassium permanganate or potassium persulfate. Substances with the potential to donate electron will convert blue-green colored ABTS radical solution into a colorless neutral form. The ABTS scavenging activity is widely used to evaluate radical scavenging potential of various plants $[17,33,41-47]$. In the present study, we determined the antiradical activity of $N$. plumbaginifolia by ABTS assay, and the result is shown in Fig. 3. The extract was found to scavenge ABTS radicals in a dose-dependent manner with an $\mathrm{IC}_{50}$ value of $13.51 \mu \mathrm{g} / \mathrm{ml}$. The scavenging potential of ascorbic acid $\left(\mathrm{IC}_{50}\right.$ value $2.48 \mu \mathrm{g} / \mathrm{ml}$ ) was higher than that of extract. Although the extract of $N$. plumbaginifolia exhibited lower scavenging potential when compared to ascorbic acid, it is clear from the result of this study that the extract possesses electron-donating potential, and hence, it can act as a free radical scavenger.

\section{CONCLUSIONS}

Plants have been widely used as a remedy against various ailments/ disorders. In the present study, we observed antibacterial, insecticidal, and antiradical potential of $N$. plumbaginifolia. In a suitable form, the plant can be exploited for treating infectious diseases, oxidative damage caused by free radicals and for controlling insect vectors which transmit viral infections such as dengue and chickungunya. The observed bioactivites could be related to the phytochemicals present in the plant which are to be isolated, characterized, and tested for their potential as antibacterial, free radical scavenging, and insecticidal agents.

\section{ACKNOWLEDGMENTS}

Authors would like to thank the Head of the Department of Microbiology and Principal of S.R.N.M.N College of Applied Sciences, for providing facilities. Authors express sincere thanks to N.E.S for moral support.

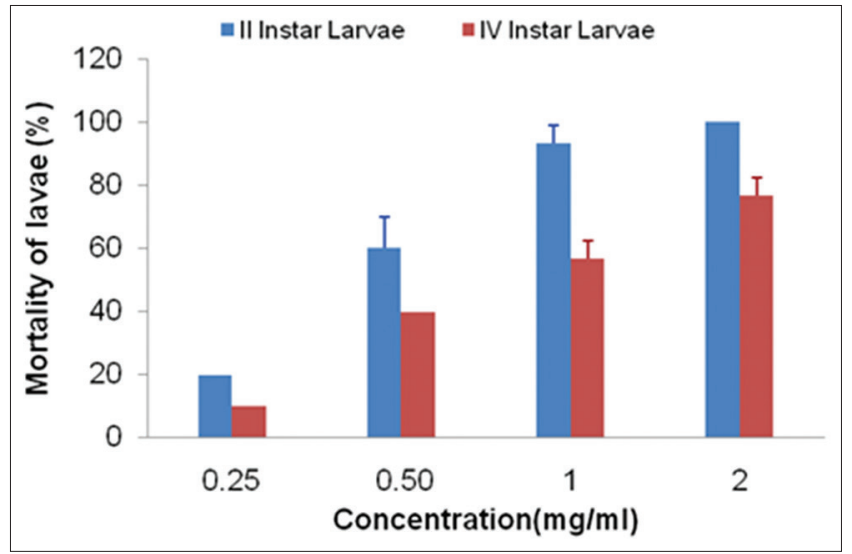

Fig. 1: Mortality of larvae (\%) at different concentrations of extract

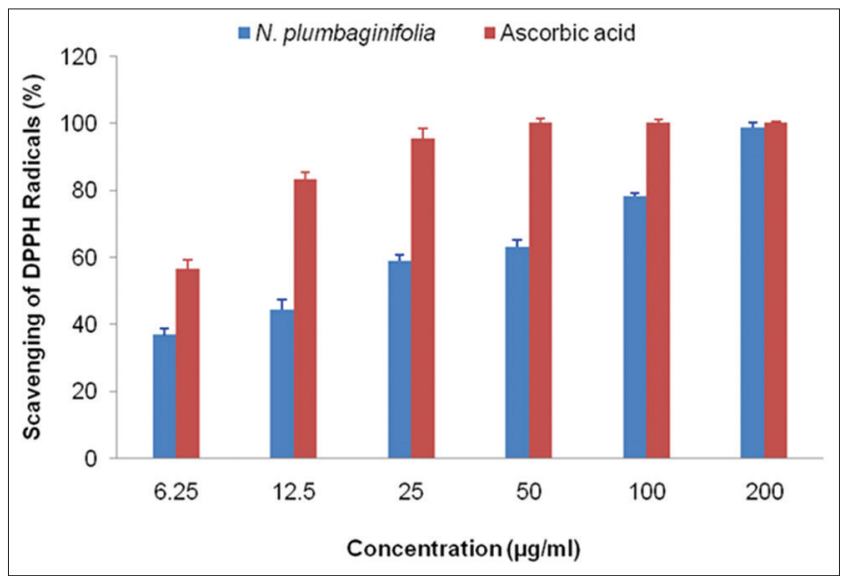

Fig. 2: Scavenging of 1,1-diphenyl-2-picrylhydrazyl radicals by Nicotiana plumbaginifolia

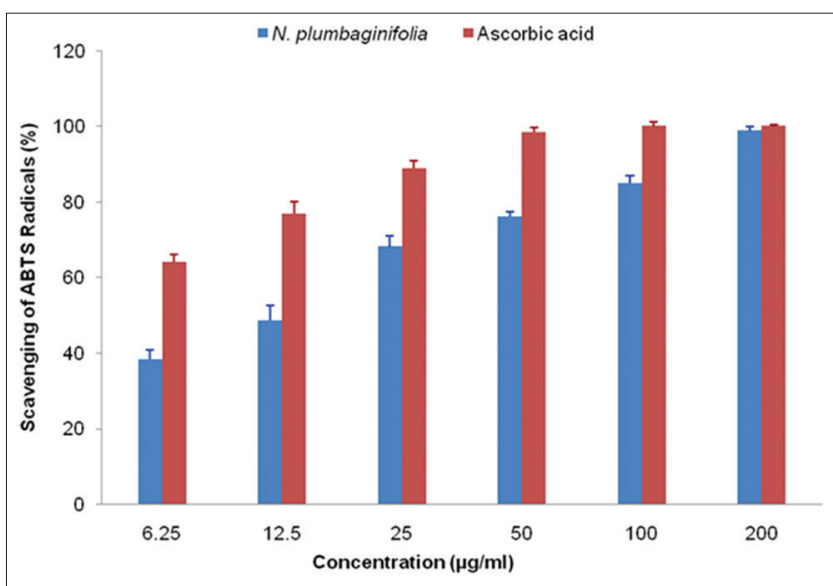

Fig. 3: Scavenging of 2,2-azinobis 3-ethylbenzothiazoline 6-sulfonate radicals by Nicotiana plumbaginifolia

Authors also thank Prof. D. Rudrappa for helping in collection and identification of plant material.

\section{REFERENCES}

1. Rose RI. Pesticides and public health: Integrated methods of mosquito management. Emerg Infect Dis 2001;7(1):17-23.

2. Shaalan EA, Canyon D, Younes MW, Abdel-Wahab H, Mansour AH. A review of botanical phytochemicals with mosquitocidal potential. 
Environ Int 2005;31(8):1149-66.

3. Poopathi S, Tyagi BK. The challenge of mosquito control strategies: From primordial to molecular approaches. Biotechnol Mol Biol Rev 2006;1(2):51-65.

4. Vinayaka KS, Swarnalatha SP, Preethi HR, Surabhi KS, Kekuda PT, Sudharshan SJ. Studies on in vitro antioxidant, antibacterial and insecticidal activity of methanolic extract of Abrus pulchellus Wall (Fabaceae). Afr J Basic Appl Sci 2009;1(5-6):110-6.

5. Kaushik R, Saini P. Screening of some semi-arid region plants for larvicidal activity against Aedes aegypti mosquitoes. J Vector Borne Dis 2009;46(3):244-6.

6. Samidurai K, Mathew N. Bioassay guided fractionation and GCMS analysis of Euphorbia lactea extract. Int J Pharm Pharm Sci 2014;6(4):344-7.

7. Ghosh A, Chowdhury N, Chandra G. Plant extracts as potential mosquito larvicides. Indian J Med Res 2012;135(5):581-98.

8. Singh A, Bhattacharya K, Chandra G. Efficacy of Nicotiana plumbaginifolia (Solanaceae) leaf extracts as larvicide against malarial vector Anopheles stephensi Liston 1901. Int J Pharm Bio Sci 2015;6(1):860-8.

9. Mallikarjuna PB, Rajanna LN, Seetharam YN, Sharanabasappa GK. Phytochemical studies of Strychnos potatorum L.f. - A medicinal plant. E J Chem 2007:4(4):510-8.

10. Doughari JH, Human IS, Bennade S, Ndakidemi PA. Phytochemicals as chemotherapeutic agents and antioxidants: Possible solution to the control of antibiotic resistant verocytotoxin producing bacteria. J Med Plants Res 2009;3(11):839-48.

11. Pandey AK, Kumar S. Perspective on plant products as antimicrobial agents: A review. Pharmacologia 2013;4(7):469-80

12. Khan MS, Sayeed SH, Uddin MH, Akter L, Ullah MA, Jahan S, et al. Screening and evaluation of antioxidant, antimicrobial, cytotoxic, thrombolytic and membrane stabilizing properties of the methanolic extract and solvent-solvent partitioning effect of Vitex negundo bark. Asian Pac J Trop Dis 2013;3(5):393-400.

13. Ahmad M, Wajid M. Plants as potential source of antimicrobial agents. J Pharm Altern Med 2013;2(3):18-25.

14. Srivastava J, Chandra H, Nautiyal AR, Kalra SJ. Antimicrobial resistance (AMR) and plant-derived antimicrobials (PDAms) as an alternative drug line to control infections. 3 Biotech 2014:4(5):451-60.

15. Hossain MA, Latif MA, Sarker BC, Jahan N. Importance of some Bangladeshi ethnomedicinal plants: A review. Eur J Med Plants 2016;16(4):1-14

16. Driss D, Kaoubaa M, Mansour RB, Kallel F, Abdelmalek BE, Chaabouni SE. Antioxidant, antimutagenic and cytotoxic properties of essential oil from Corchorus olitorius L. Flowers and leaf. Free Radic Antioxid 2016;6(1):34-43.

17. Raghavendra HL, Kekuda PT, Akarsh S, Ranjitha MC, Ashwini HS. Phytochemical analysis, antimicrobial and antioxidant activities of different parts of Pleocaulus sessilis (Nees) Bremek (Acanthaceae). Int J Green Pharm 2017;11(2):98-107.

18. Lobo V, Patil A, Phatak A, Chandra N. Free radicals, antioxidants and functional foods: Impact on human health. Pharmacogn Rev 2010;4(8):118-26.

19. Maruthappan V, Shree SK. A report on the antioxidant activity of the powder of the entire plant of Phyllanthus reticulatus poir. Int J Green Pharm 2010;4(4):265-9.

20. Pavithra GM, Siddiqua S, Naik AS, Kekuda PT, Vinayaka KS. Antioxidant and antimicrobial activity of flowers of Wendlandia thyrsoidea, Olea dioica, Lagerstroemia speciosa and Bombax malabaricum. J Appl Pharm Sci 2013;3(6):114-20.

21. Krishnamoorthy K, Krishnaswamy T, Subramaniam P, Sellamuthu M. Quantification of phytochemicals and in vitro antioxidant potential of various solvent extracts of certain species of Acanthaceae. Int J Green Pharm 2014;8:58-64.

22. Singh KP, Daboriya V, Kumar S, Singh S. Antibacterial activity and phytochemical investigations on Nicotiana plumbaginifolia Viv. (Wild tobacco). Rom J Biol Plant Biol 2010;55(2):135-42

23. Shahriar M, Chowdhury SA, Imam, MZ, Datta BK. Analgesic and neuropharmacological activities of methanol extract from the leaf of Nicotiana plumbaginifolia Viv. Bangladesh Pharm J 2015;18(2):85-9.

24. Ajaib M, Fatima S, Khan KM, Perveen S, Shah S. Nicotiana plumbaginifolia: A rich antimicrobial and antioxidant source. J Chem Soc Pak 2016;38(1):143-9.

25. Available from: http://www.florakarnataka.ces.iisc.ac.in/hjcb2/ herbsheet.php?id=4119\&cat=1.

26. Nawaz MM, Hossain M, Karim M, Khan M, Jahan R, Rahmatullah M. An ethnobotanical survey of Rajshahi district in Rajshahi division, Bangladesh. Am Eur J Sustain Agric 2009;3(2):143-50.

27. Rothe SP. Exotic medicinal plants from West Vidarbha region of Maharashtra - III. J Ecobiotechnol 2011:3(9):11-3.

28. Sharma J, Gaur RD, Gairola S, Painuli RM, Siddiqi TO. Traditional herbal medicines used for the treatment of skin disorders by the Gujjar tribe of Sub-Himalayan tract, Uttarakhand. Indian J Tradit Knowl 2013;12(4):736-46

29. Singh TT, Sharma HM, Devi AR, Sharma HR. Plants used in the treatment of piles by the scheduled caste community of Andro village in Imphal East district, Manipur (India). J Plant Sci 2014;2(3):113-9.

30. Sharma DL, Devi SL, Singh BL, Singh CT. Medicinal plants found in Imphal Valley used in treatments of various ailments. Int J Sci Res 2015;4(12):282-6

31. Ansar A, Naresh L, Simon S. Effect of different plant extracts as antifungal agents against Alternaria alternata causing leaf blight disease of cabbage (Brassica oleracea). Int J Pharm Bio Sci 2015;6(2):176-81.

32. Shah AS, Khan RA, Ahmed M, Muhammad N. Hepatoprotective role of Nicotiana plumbaginifolia Linn. Against carbon tetrachloride-induced injuries. Toxicol Ind Health 2016;32(2):292-8.

33. Kekuda PT, Siddiqha A, Pushpavathi D, Vinayaka KS, Raghavendra HL. Radical scavenging, cytotoxic and antimicrobial activity of Flacourtia indica (Burm. f.) Merr. Med Health Sci Res J 2017;1(1):76-82.

34. Cowan MM. Plant products as antimicrobial agents. Clin Microbiol Rev 1999;12(4):564-82.

35. Fankam AG, Kuiate JR, Kuete V. Antibacterial and antibiotic resistance modifying activity of the extracts from Allanblackia gabonensis, Combretum molle and Gladiolus quartinianus against gram-negative bacteria including multi-drug resistant phenotypes. BMC Complement Altern Med 2015:15:206

36. Rios JL, Recio MC, Villar A. Screening methods for natural products with antimicrobial activity: A review of the literature. J Ethnopharmacol 1988;23(2-3):127-49.

37. Das K, Tiwari RK, Shrivastava DK. Techniques for evaluation of medicinal plant products as antimicrobial agent: Current methods and future trends. J Med Plants Res 2010;4(2):104-11.

38. Balouiri M, Sadiki M, Ibnsouda SK. Methods for in vitro evaluating antimicrobial activity: A review. J Pharm Anal 2016;6(2):71-9.

39. Blois MS. Antioxidant determinations by the use of a stable free radical. Nature 1958;181:1199-200

40. Molyneux P. The use of the stable free radical diphenylpicrylhydrazyl (DPPH) for estimating antioxidant activity. Songklanakarin J Sci Technol 2004;26(2):211-9.

41. Thaipong K, Boonprakob U, Crosby K, Cisneros-Zevallos L, Byrne DH. Comparison of ABTS, DPPH, FRAP, and ORAC assays for estimating antioxidant activity from guava fruit extracts. J Food Compost Anal 2006;19:669-75.

42. Krishna MS, Nair JA. Antibacterial, cytotoxic and antioxidant potential of different extracts from leaf, bark and wood of Tectona grandis. Int J Pharm Sci Drug Res 2010;2(2):155-8.

43. Wan C, Yu Y, Zhou S, Liu W, Tian S, Cao S. Antioxidant activity and free radical-scavenging capacity of Gynura divaricata leaf extracts at different temperatures. Pharmacogn Mag 2011;7(25):40-5.

44. Shalaby EA, Shanab SM. Comparison of DPPH and ABTS assays for determining antioxidant potential of water and methanol extracts of Spirulina platensis. Indian J Geo Mar Sci 2013;42(5):556-64.

45. Zhen J, Villani TS, Guo Y, Qi Y, Chin K, Pan MH, et al. Phytochemistry, antioxidant capacity, total phenolic content and anti-inflammatory activity of Hibiscus sabdariffa leaves. Food Chem 2016;190:673-80.

46. Fidrianny I, Rahmiyani I, Wirasutisna KR. Antioxidant capacities from various leaves extracts of four varieties mangoes using DPPH, ABTS assays and correlation with total phenolic, flavonoid, carotenoid. Int J Pharm Pharm Sci 2013;5(4):189-94.

47. Indu $\mathrm{H}$, Seenivasan R. In vitro antioxidant activity of selected seaweeds from southeast coast of India. Int J Pharm Pharm Sci 2013;5(2):474-84. 